\title{
Uso de la temperatura y propóleos en el tratamiento alternativo de semillas de calabacín
}

\author{
Use of temperature and propolis in the alternative treatment of zucchini seeds \\ Natália de Brito Lima Lanna1, Estefânia Martins Bardiviesso ${ }^{1}$, \\ Ariel Santivañez Aguilar ${ }^{1 *}$, Carolina Paz Ayala Pérez, Samuel Contreras ${ }^{2}$, \\ Pâmela Gomes Nakada-Freitas ${ }^{3}$, Antonio Ismael Inácio Cardoso ${ }^{1}$
}

\begin{abstract}
RESUMEN
En el sistema de producción orgánica está prohibido el uso de fungicidas para el tratamiento de semillas. En consecuencia, la termoterapia y el propóleos son métodos alternativos en el control de patógenos de semillas permitidas en este sistema. El objetivo de este estudio fue evaluar la germinación y el vigor de semillas de calabacín sometidas a termoterapia y concentraciones de propóleos. En el tratamiento con termoterapia húmeda se evaluaron tres temperaturas $\left(50,55\right.$ y $\left.60^{\circ} \mathrm{C}\right)$ en experimentos separados. Para cada temperatura, se estudiaron cuatro tiempos de inmersión de las semillas (15, 30, 45 y 60 minutos, además del control sin tratamiento - tiempo 0). En el tratamiento con termoterapia seca se evaluaron 4 tiempos $(24,48,72$ y 96 horas) en que las semillas permanecieron en la estufa a $70^{\circ} \mathrm{C}$ con temperatura constante. En el tratamiento con propóleos se estudiaron seis concentraciones $(0,0 ; 0,2 ; 0,4 ; 0,6 ; 0,8$ y $1,0 \%)$, con posterior lavado o no lavado de las semillas, totalizando 12 tratamientos. El análisis de germinación se realizó en delineamiento completamente casualizado, con cuatro repeticiones, y se evaluó la germinación y el vigor (índice de velocidad de germinación). La termoterapia seca no afectó la germinación ni el vigor de las semillas. La termoterapia húmeda a $50^{\circ} \mathrm{C}$ redujo la germinación, a pesar de que los valores todavía están dentro de los padrones comerciales de germinación. Con $55^{\circ} \mathrm{C}$ el tratamiento tiene que ser por menor período de tiempo, hasta 30 minutos, y no se recomienda el tratamiento a $60{ }^{\circ} \mathrm{C}$. En cuanto al propóleos, altas concentraciones redujeron la germinación, a pesar de que los valores todavía están dentro de los padrones comerciales de germinación.
\end{abstract}

Palabras clave: Cucurbita pepo, termoterapia, semillas orgánicas.

\begin{abstract}
In the organic production system, the use of fungicides for the treatment of seeds is prohibited. On account of that, thermotherapy and propolis are alternative methods of control of pathogens in seeds allowed in this system. This study was conducted to evaluate the zucchini seeds' germination and vigor when subjected to thermotherapy and treatment with propolis. In the treatment with moist thermotherapy, three temperatures $\left(50,55\right.$, and $\left.60^{\circ} \mathrm{C}\right)$ were evaluated in separate experiments. Four times of immersion of the seeds $(15,30,45$, and 60 minutes, besides the control treatment - time 0$)$ were tested for each temperature. In the dry thermotherapy treatment, four times $(24,48,72$, and 96 hours) were evaluated in which the seeds remained in the oven at a constant temperature of $70{ }^{\circ} \mathrm{C}$. In the treatment with propolis, six concentrations $(0.0,0.2,0.4,0.6,0.8$, and $1.0 \%)$ were studied, with subsequent washing or without washing of the seeds, totaling 12 treatments. The germination test was installed in the complete randomized design, with four repetitions, and germination and vigor (germination speed index) were evaluated. The dry thermotherapy did not affect the germination and vigor of seeds. The moist thermotherapy at $50^{\circ} \mathrm{C}$ reduced germination; besides, the values are within germination patterns. At $55^{\circ} \mathrm{C}$, the treatment has to be for a lesser time, until 30 minutes, and it is not recommended the treatment at $60^{\circ} \mathrm{C}$. For propolis, the treatment resulted in a little reduction in germination in the highest contents, the values are within the germination patterns.
\end{abstract}

Keywords: Cucurbita pepo, thermotherapy, Organic seeds.

\footnotetext{
1 UNESP - Universidade Estadual Paulista, Faculdade de Ciências Agrônomicas (FCA), Botucatu, São Paulo, Brasil.

2 Facultad de Ingeniería Forestal y Agronomía de la Pontificia Universidad Católica de Chile, Santiago Chile.

3 UNESP - Universidade Estadual Paulista, Faculdade de Ciências Agrárias e Tecnológicas (FCAT), Dracena, São Paulo, Brasil.

* Autor para correspondencia: ariel_trex89@hotmail.com
}

Fecha de Recepción: 14 de Octubre, 2019.

Fecha de Aceptación: 1 de Agosto, 2019. 


\section{Introducción}

La olericultura es pionera en la producción orgánica, pero todavía enfrenta algunos problemas como la oferta reducida de semillas producidas en este sistema para atender el proceso de certificación durante toda la cadena. Esto se debe a que la mayoría del cultivo orgánico de hortalizas todavía es producido con semillas convencionales (Pereira et al., 2015).

Una semilla que contiene patógenos, independientemente de si es transmisible o no, puede afectar el vigor, además de perjudicar también el rendimiento de los cultivos en el campo (LUZ, 2003). El período comprendido entre la siembra y el establecimiento de las plántulas es crucial para la producción olerícola (Machado, 2009). Algunos patógenos cuando están presentes en las semillas pueden perjudicar el desarrollo inicial o incluso causar la muerte de las plántulas. La eliminación o control de patógenos asociados a las semillas se logra de forma eficiente a través de tratamientos químicos, biológicos y físicos (Cunha et al., 2017).

No siempre es posible la obtención de lotes de semillas sin la presencia de microorganismos indeseables. Por eso, la mayoría de las veces es recomendable el tratamiento de las semillas, aún más en hortalizas, cuyas semillas presentan un valor elevado. El costo de este tratamiento es pequeño comparado con el de las semillas (Cardoso et al., 2015). El tratamiento más común es con el uso de fungicidas; sin embargo, en el sistema de producción orgánica está prohibido utilizar estos productos para las semillas, y es necesario aplicar otros métodos o técnicas de control.

Con la creciente demanda y preocupación por alimentos más saludables, oriundos de la agricultura familiar, sin químicos y producidos en sistemas que causan menos daños al ambiente, la termoterapia es una alternativa en el tratamiento de semillas orgánicas. Esta técnica consiste en la exposición del material que se tratará a la acción del calor (húmedo o seco), en combinación con el período del tratamiento (binomio temperatura / tiempo), permitiendo el control de organismos fitopatógenos. El principio del tratamiento se basa en la diferencia de los puntos térmicos letales, es decir, la temperatura del agua debe ser superior a la temperatura letal para el patógeno, sin perjudicar las semillas (Pereira et al., 2015).

Además del tratamiento térmico existen otros tipos de tratamientos alternativos de semillas, como aplicación de aceites esenciales, extractos de plantas y propóleos. El propóleos se viene experimentando en el control de patógenos de semillas con buenos resultados (Souza et al., 2017). Según Silva et al. (2006), el propóleos está constituido por una serie de sustancias resinosas, que las abejas utilizan en la protección de la colmena contra la proliferación de microorganismos, incluyendo hongos y bacterias. Además es un producto natural, es decir, una alternativa para tratar semillas en sistema de producción orgánico.

Los estudios con tratamientos alternativos en semillas de hortalizas son restringidos. El objetivo de este trabajo fue evaluar el efecto del tratamiento térmico (calor húmedo y seco) y del propóleos sobre la germinación y vigor de semillas de calabacín producidas en sistema orgánico.

\section{Materiales y métodos}

Los experimentos se hicieron en el Laboratorio de Semillas del Departamento de Ciencias Vegetales de la Facultad de Agronomía e Ingeniería Forestal de la Pontificia Universidad Católica de Chile.

Se realizaron tres investigaciones para el tratamiento de semillas de calabacín con diferentes métodos: termoterapia húmeda, termoterapia seca y propóleos. En el método con termoterapia húmeda se evaluaron tres temperaturas (50, 55 y $60{ }^{\circ} \mathrm{C}$ ), en experimentos separados. Para cada temperatura, se estudiaron cuatro tiempos de inmersión de las semillas $(15,30,45$ y 60 minutos, además del control sin tratamiento tiempo 0). Las semillas estuvieron inmersas en agua dentro de bolsas de tejido poroso de nylon en el aparato de baño María, con temperatura y tiempo determinados. Posteriormente las semillas se enfriaron con agua corriente y se colocaron en el secador de semillas con aire forzado a $35^{\circ} \mathrm{C}$, durante 3 horas.

En la investigación con termoterapia seca se evaluaron cuatro tratamientos. Las semillas fueron colocadas en estufa con ventilación por aire forzado, a temperaturas de $70{ }^{\circ} \mathrm{C}$ durante 24 , 48, 72 y 96 horas.

En la investigación con propóleos se estudiaron doce tratamientos, resultantes del factorial $6 \times 2$. Se utilizaron seis concentraciones de propóleos $(0,0,0,2,0,4,0,6,0,8$ y $1,0 \%)$, con y sin lavado de las semillas después de ser tratadas con propóleos. Para el tratamiento con propóleos, las semillas se 
agitaron durante 30 minutos dentro de un Becker y una parte deellas se lavaron con agua destilada para retirar el exceso del producto. La otra parte no se lavó. Después de este procedimiento, las semillas se colocaron en el secador de semillas con aire forzado a $35^{\circ} \mathrm{C}$, durante 3 horas.

Para todos los experimentos se hizo la prueba de germinación, en delineamiento completamente casualizado, con cuatro repeticiones de 50 semillas.

Las semillas se colocaron para germinar sobre dos hojas de papel filtro, humedecidas con la cantidad equivalente a 2,5 veces la masa del papel y cubiertas con otra hoja de papel. Posteriormente se hicieron rollos y fueron acondicionados en germinador del tipo BOD, en posición vertical con temperatura de $25^{\circ} \mathrm{C}$ (BRASIL, 2009). Las semillas se consideraron germinadas cuando se observó la aparición de las hojas cotiledonares. El conteo final de las plántulas se realizó a los ocho días después de la siembra, con resultados expresados en porcentaje. Diariamente, siempre en el mismo horario, se evaluó la germinación para la obtención del índice de velocidad de germinación (IVG). El IVG se obtiene durante la prueba de germinación, con valores de semillas germinadas día a día, a través de la suma del número de semillas germinadas en cada día (no acumulativo), dividida por el número de días transcurridos entre la siembra y la germinación (Maguire, 1962). Cuanto mayor es el valor del IVG, mayor es la velocidad de germinación y, consecuentemente, mayor el vigor de las semillas. Los datos se sometieron a análisis de varianza y cuando fue significativo, se realizó un análisis de regresión para los tiempos de tratamientos de las semillas en el agua, calor seco y para las concentraciones de propóleos. Para los análisis se utilizó el programa estadístico SISVAR (FERREIRA, 2010).

\section{Resultados y discusión}

\section{Termoterapia seca y húmeda}

El tiempo de tratamiento de las semillas con termoterapia seca a $70{ }^{\circ} \mathrm{C}$ no afectó la germinación ni el vigor (IVG), y se obtuvo un promedio del $98,4 \%$ y $49,7 \%$, respectivamente. Este porcentaje de germinación está por encima del mínimo aceptado para comercialización en Brasil por el MAPA que es del $80 \%$. Sin embargo, según Cardoso et al. (2015), considerando la competitividad entre las empresas de producción de semillas, estos padrones oficiales del MAPA están desfasados con la realidad del mercado, por lo que es difícil la buena aceptación por parte de los productores, de semillas de cucurbitáceas con menos de 85 a $90 \%$ de germinación. Por lo tanto, las semillas pueden ser consideradas aptas para la comercialización, incluso cuando son tratadas a una temperatura de $70{ }^{\circ} \mathrm{C}$ con calor seco por $96 \mathrm{~h}$. La germinación con termoterapia húmeda a temperaturas de 50 y $55^{\circ} \mathrm{C}$ se ajustó al modelo lineal decreciente y a $60^{\circ} \mathrm{C}$ al modelo cuadrático (Figura 1). Para cada un minuto más de tratamiento, se observa una reducción en la germinación de 0,11 y $0,60 \%$ en los tratamientos a $50{ }^{\circ} \mathrm{C}$ y $55^{\circ} \mathrm{C}$, respectivamente. A $60{ }^{\circ} \mathrm{C}$ el tratamiento se mostró inviable, con drástica reducción en la germinación y muerte de todas las semillas (germinación del 0\%) con menos de 30 minutos de tratamiento. En consecuencia, se puede afirmar que la termoterapia con agua caliente afecta la germinación de las semillas de calabacín.

Sin embargo, incluso con reducción de la germinación, en el tratamiento a $50{ }^{\circ} \mathrm{C}$ el valor estimado en el mayor tiempo (60 minutos) aún fue elevado $(93 \%)$, mientras que a $55^{\circ} \mathrm{C}$ la reducción fue grande, considerando que a partir de 54 minutos de tratamiento la germinación fue inferior al mínimo aceptado para su comercialización por el MAPA (75\%).

Para el IVG la temperatura de $50{ }^{\circ} \mathrm{C}$ no tuvo efecto significativo, y se obtuvo un promedio de 48,1 . Sin embargo, con temperatura de $55^{\circ} \mathrm{C}$ los datos se ajustaron al efecto lineal decreciente y por cada un minuto más de tratamiento, el IVG disminuyó 0,47 (Figura 1). Pero con temperatura de $60^{\circ} \mathrm{C}$ se registró efecto cuadrático negativo, con mínimo IVG de 41.

Los resultados observados en la literatura varían de acuerdo con la temperatura y el tiempo de tratamiento y principalmente de acuerdo con la especie. Toite; Hernández-Pérez (2005), en semillas de espinacas, constataron reducción de la germinación a menos del $50 \%$ cuando fueron expuestas a $55^{\circ} \mathrm{C}$ durante 40 minutos. También Muniz (2001) aseguró que la germinación de semillas de tomate se redujo y la emergencia fue nula cuando las semillas se trataron a $50^{\circ} \mathrm{C}$ por 30 minutos. Braga et al. (2010) demostraron que el tratamiento de semillas de tomate a 52, 53, 54 y $55^{\circ} \mathrm{C}$ durante 30 minutos presentó un porcentaje de 


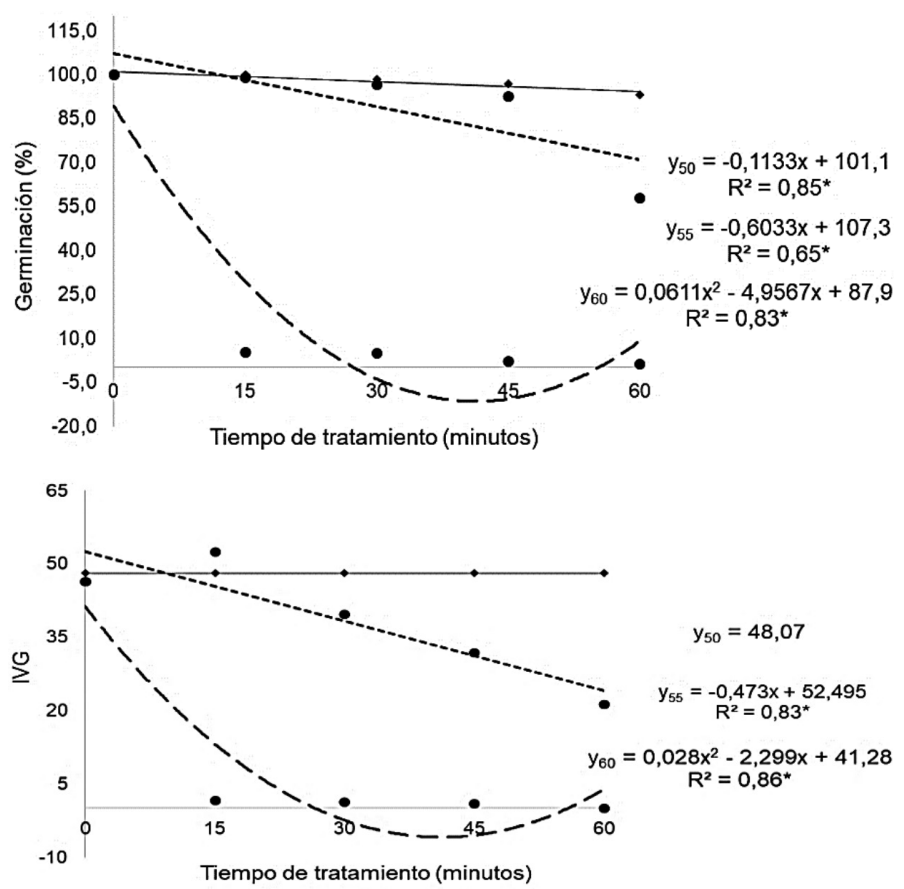

Figura 1. Germinación e índice de velocidad de germinación (IVG) de semillas de calabacín tratadas con termoterapia húmeda con temperaturas de $50^{\circ} \mathrm{C}$ (y 50$), 55^{\circ} \mathrm{C}$ (y 55 ) y $60^{\circ} \mathrm{C}$ (y 60). FAIF/PUC, Santiago de Chile - Cl, 2017.

germinación media menor que aquellas no tratadas con termoterapia. Sin embargo, Costa et al. (2011) trataron semillas de tomate con agua a $50{ }^{\circ} \mathrm{C}$ por 25 y 30 minutos sin causar daños en su calidad fisiológica.

Según Coutinho et al. (2007), el tratamiento con agua caliente puede causar desnaturalización de los tejidos externos y/o rompimiento del tegumento de las semillas, deteriorándolas rápidamente en comparación con las semillas no tratadas por termoterapia. Sin embargo, como se ve en este trabajo, semillas de pepino pueden soportar una temperatura de $50^{\circ} \mathrm{C}$, disminuyendo la germinación, y aun así se encuentran con valores aceptables para ser comercializadas. A $55^{\circ} \mathrm{C}$ el tratamiento tiene que ser por menor período de tiempo, hasta 30 minutos, y no se recomienda hacerlo a $60^{\circ} \mathrm{C}$

\section{Tratamiento con propóleos}

No se observó interacción entre los factores lavado de semillas y concentración de propóleos. Tampoco se reportó efecto del factor lavado, o no, de las semillas después de ser tratadas. Para las concentraciones de propóleos los datos se ajustaron al modelo cuadrático, con aumento pequeño en la germinación hasta la concentración de $0,3 \%$ de propóleos, con máxima germinación estimada en 99\% y reducción con concentraciones superiores (Figura 2). Sin embargo, con concentración del 1,0\% la germinación se redujo a $95 \%$ y este porcentaje es apto para la comercialización de semillas, de acuerdo a la normativa del MAPA y exigencias de las empresas. Para el vigor (IVG) no se verificó diferencia estadística, y se obtuvo media de 49,4.

Souza et al. (2017), al estudiar el extracto de propóleos en el control del hongo Penicillium sp. en semillas de coliflor, constataron que la concentración del $20 \%$ impide el desarrollo del hongo Penicillium sp. in vitro y no afecta la calidad fisiológica de las semillas. También Vieira et al. (2010), al experimentar el extracto de propóleos en concentraciones de 2, 4, 8 y $16 \mathrm{ml}^{-1}$ bajo agitación por 30 y 60 minutos, sobre algunos hongos fitopatógenos en semillas de frijol, detectaron efecto en la reducción de crecimiento de estos hongos, sin perjudicar la calidad fisiológica de las semillas.

Se cree que altas concentraciones de propóleos pueden afectar el embrión de las semillas, resultando plántulas anormales, según el estudio de King-Díaz et al. (2015). Estos autores verificaron 


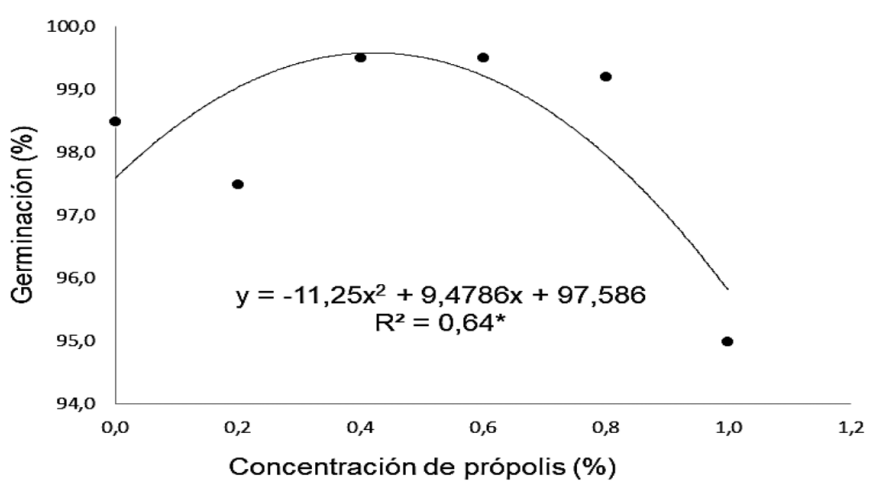

Figura 2. Germinación de semillas de calabacín en función de la concentración de propóleos. FAIF/PUC, Santiago de Chile - Cl, 2017.

que los flavonoides interfieren en el flujo de electrones de la reacción de Hill (fotolisis del agua), afectando en el desarrollo de plantas. Según Souza et al. (2017), además de este efecto en reacciones metabólicas, concentraciones de 0 a $20 \%$ pueden desecar el eje embrionario. En la investigación no se observaron estos efectos negativos del propóleos. Sin embargo, se estudiaron concentraciones considerablemente más bajas $(0,0$ a $1,0 \%)$ que la mayoría de los trabajos citados. Aún existen pocas investigaciones con la utilización de propóleos en el tratamiento de semillas de hortalizas, como para poder afirmar cuál es la concentración más adecuada para el control de hongos patogénicos sin perjudicar la calidad fisiológica de las semillas. Además cada especie puede responder de manera diferente, como sucede con la termoterapia. Por lo tanto, se puede concluir que el uso de propóleos puede ser un método alternativo eficiente para el sector de semillas producidas en el sistema orgánico, pero todavía se necesitan más estudios.

\section{Conclusiones}

La termoterapia seca a $70{ }^{\circ} \mathrm{C}$ no perjudica la germinación de las semillas ni el vigor.

Las semillas de calabacín, cv. Caserta, pueden soportar temperaturas de $50{ }^{\circ} \mathrm{C}$ hasta 60 minutos. A $55{ }^{\circ} \mathrm{C}$ el tratamiento tiene que ser por menor período de tiempo, hasta 30 minutos, y no se recomienda el tratamiento a $60{ }^{\circ} \mathrm{C}$.

Las concentraciones estudiadas de propóleos, con y sin lavado después del tratamiento, afectaron la calidad fisiológica de las semillas de calabacín. Sin embargo, son viables para la comercialización.

\section{Literatura citada}

Braga, M.P.; Olinda, R.A.; Homma, S.R.; Dias, C.T.S.

2010. Relações entre termoterapia, germinação, vigor e sanidade de semente de tomate. Revista Brasileira de Sementes, Londrina, PR, 32(1): 101-110.

BRASIL.

2009. Regras para análise de sementes. Ministério da Agricultura e Reforma Agrária. Brasília, DF, Brasil. 399 p.

Cardoso, I.I.A.; Lanna, L.B.N.; Silva, N.P.; Nakada, G.P.; Santos, P.; Pierozzi, G.C.; Kronka, Z.A.

2015. Germination, vigor and pathogen incidence in broccoli seed treated with Carboxin + Thiram. African Journal of Agricultural Research, 10: 1-5.

Costa, I.J.S.; Soares, E.P.S.; Sales, N.L.P.; Azevedo, D.M.Q.;

Rocha, A.P.; Aquino, C.F.

2011. Tratamento de sementes de tomate cereja visando sanidade e germinação através da termoterapia. Cadernos de Agroecologia, 6(2): 1-5.
Coutinho, W.M.; Silva-Mann, R.; Vieira, M-G. G.C., Machado, C F.; Machado, J.C.

2007. Qualidade sanitária e fisiológica de sementes de milho submetidas à termoterapia e condicionamento fisiológico. Fitopatologia Brasileira, 32: 458-464.

Cunha, R.P.; Carvalho, I.L.; Olsen, D.; Vieira, J.F.; Soares, V.N.; Tunes, L.M.

2017.Termoterapia no controle de patógenos associados às sementes de abóbora. Tecnol. \& Ciên. Agropoc., João Pessoa, 11(2): 53-57.

Ferreira, D.F.

2010. Sisvar: a computer statistic al analysis system. Ciência e Agrotecnologia, 35(6):1039-1042.

King-Díaz, B.; Granados-Pineda, J.; Bah, M.; Rivero-Cruz, J.; Lotina-Hennsena, B.

2015. Mexican propolis flavonoids affect photosynthesis and seedling growth. Journal of Photochemistry and Photobiology B: Biology, 151. 213-220. 
LUZ, W.C.

2003. Combinação dos tratamentos biológicos e químico de sementes de milho. Fitopatologia Brasileira, 28(1): 37-40.

Machado, J.C.; Souza, R.M.

2009. Tratamento de Sementes de Hortaliças para controle de patógenos: princípios e aplicações. In: Nascimento, W. N. (Org.). Tecnologia de Sementes de Hortaliças. Embrapa Hortaliças. Brasília, DF, Brasil. P. 247-272.

Machado, J.C.

2000. Tratamento de sementes no controle de doenças. LAPS. Lavras, Brasil. 138 p.

Muniz, M.F.B.

2001. Control of microorganisms associated with tomato seeds using thermotherapy. Revista Brasileira de Sementes, Brasília, 23(1): 176-280.

Pereira, R.B.; Silva, P.P. Da; Nascimento, W.M.; Pinheiro, J.B. 2015. Tratamento de sementes de hortaliças. Embrapa. Brasília, DF, Brasil. 16 p.

Silva, R.A.; Rodrigues, A.E.; Ribeiro, M.C.M.; Custódio, A.R.; Andrade, N.E.D.; Pereira, W.
2016. Características físico-químicas e atividade antimicrobiana de extratos de própolis da Paraíba, Brasil. Ciência Rural, Santa Maria, 36(6): 1842-1848.

Souza, E.P.; Perino, F.H.B.; Moscato, B.S.; Freitas, P.G.N.; Blumer, S.; Cardoso, A.I.I.; Bonini, C.S.B.; Bonini Neto, A. 2017. Extrato de própolis no controle de Penicillium sp. e na qualidade de sementes de couve-flor. Brazilian Journal of Biosystems Engineering, 11(2): 135-141.

Toite, L.J. Du; Hernández-Pérez, P.

2005. Efficacy of hot water and chlorine for eradication of Cladosporium variabile, Stemphylium botryosum, and Verticillium dahliae from spinach seed. Plant Disease, Saint Paul, 89: 1305-1312.

Vieira, G. H. da C.; Dardani, P.; Andrade, W.; Barbosa, C.A.F.

2010. Efeitos do extrato de própolis sobre a qualidade sanitária e fisiológica de sementes de feijão. Resumos do III Seminário de Agroecologia de MS. Cadernos de Agroecologia, 15(1) 